\title{
"GENOME SEQUENCE ANALYSIS OF SOLANUM LYCOPERSICUM SHOWING THE SITE OF RESTRICTION ENZYMES OF RNA SEQUENCE BY APPLYING NEB CUTTER AS BIOINFORMATICS TOOL”
}

\author{
UMA KUMARI ${ }^{1} \&$ ASHOK KUMAR CHOUDHARY ${ }^{2}$ \\ ${ }^{1}$ Department of Biotechnology, Jharkhand Ray University, Ranchi, Jharkhand, India \\ ${ }^{2}$ Department of Botany, Ranchi University, Ranchi, Jharkhand, India
}

\begin{abstract}
Sequencing the genome of the crop Solanum Lycopersicum will help to identify beneficial gene in other plant relative of tomato such as potato, pepper. As well as, using this genome information to develop a wide variety of beneficial traits, the tomato genomic resources database is an online and interactive relational database, developed using open resources software. NEB offers several helpful interactive tools for research and experimental deasign.NEB cutter accepts an input sequence, picked up from a local file or retrieved from NCBI as a gene bank file, via its accession number. The DNA restriction pattern with known restriction enzymes was determined. NEB cutter is a program available via a web server (http:/tools.neb.com/Neb cutter) that will accept an input DNA/RNA sequence. NEB offers several helpful interactive tools for research and experimental design. NEB cutter accepts an input sequence, picked up from a local file or retrieved from NCBI as a gene bank file, via its accession number.

KEYWORDS: Restriction Pattern, Genome Database, DNA Restriction Enzymes, Restriction Analysis Tools, Restriction Mapping, Neb Cutter \& DNA Methylation
\end{abstract}

Received: Apr 12, 2017; Accepted: May 05, 2017; Published: Jun 06, 2017; Paper Id.: IJBTRJUN20175

\section{INTRODUCTION}

The tomato genome resources database is an interactive relational database developed using open sources bioinformatics software. Sequence analysis created a huge impact in solanaceae research, using a sequence of RNA /DNA requires the use of restriction enzymes. The analysis of large non-overlapping open reading frames within a given nucleotide sequence was determined by using NEB Cutter V2.0 tools(http://nc2.neb.com/Neb cutter2/) for each sequence, this tool determine possible number of cleavage in the form of blunt end and 5" and 3" sticky ends extension, while identified number of enzymes. A Neb cutter popular tool for sequence restriction mapping also identifies silent restriction sites. The Solanaceae or nightshade family consists of more than 3000 species with great diversity in terms of habitat, habitat and morphology. Solanum is the largest genus in the family, and include tomato (selenium lycopersicum) and various other species of economics importance. Here DNA methylation occurs in CPG dinucleotide context (where cytosine is followed by a guanine). The CG island is a short stretch of DNA in which the frequency of the CG sequence is higher than other regions. CPG Island where "P" simply indicates that C and G are connected photo disaster bond. Tomatoes have been used extensively for genetic studies because of several reasons such as its diploid genome, short generation time, and efficient transformation technology. The data can be submitted and accessed via the World Wide Web (Mount. David 2004). REBASE (http://www.neb.com/rebase). Importantly, its table of recognition sites is updated daily from REBASE and it marks all sites that are potentially affected by DNA 
methylation (Dam, DCM, etc.). Fast a format is a text based format for representing either nucleotide sequence or protein sequence (Higgins, D. G.; Sharp, P. M. (1989). The format originate from the fast a software package. For DNA and Protein, it is represented in one letter IUPAC nucleotide code and amino acid code.

\section{MATERIALS AND METHODS}

The National Center of Biotechnology Information (NCBI) is a multidisciplinary research group that serves as sources for molecular biology information. This group is developing new method to deal with the volume and complexity of data searching and methods that can analyze the structure and function of macromolecules creating computerized systems for storing and analyzing data. The primary database retrieval system at NCBI links together several databases including gene bank. This Method uses the neb cutter consisting of a set of cooperating program modules. It produces variety of output including restriction enzymes maps. The analysis of large non-overlapping open reading frame within a given nucleotide sequence was determined by using NEB cutter V 2.0 tool (http://nc2.ncb.com/NEB cutter 2) for each sequence. This tool determines possible number of cleavage in the form of blunt end cut 5 and 3 sticky ends extension, while identified number of enzyme there. A NEB cutter popular, tool for sequence restriction mapping also identifies silent restriction sites.

$\begin{array}{ll}\text { Database Name } & \text { Web Services Type: URL } \\ \text { NCBI } & \text { E- Utility web services (http://www.cbi.nlm.nih.gov } \\ \text { FASTA } & \text { www.ebi.ac.uk/tools } \\ \text { EMBL/EBI } & \text { EMBL- EBI web services (http://www.ebi.ac.uk/tools/ } \\ \text { Uniprot KB } & \text { Programmatic access services (http://www.uniprot.org) } \\ \text { EBI/ftp site: } & \underline{\text { ftp://ftp.ebi.ac.uk/pub/software/clustalw2/ }} \\ \text { NEB Cutter } & \underline{\text { http://www.labtools.us/neb Cutter-v2-0 }} \\ \text { REBASE } & \underline{\text { http://www.neb.com/rebase. }} \\ \text { ORF } & \underline{\text { https://www.ncbi.nlm.nih.gov/orffinder }}\end{array}$

\section{RESULTS AND DISCUSSIONS}

A number of proprietary plasmids are digested to completion with appropriate restriction enzymes, to yield bands suitable for use as molecular weight standards, for agarose gel electrophoresis. The digested DNA includes fragment ranging from 100-1,517 base pairs. It shows as a DNA ladder with size ranging from 100kb to $3 \mathrm{~kb}$ for use in agarose gel electrophoresis. Each ladder contains nucleic acid fragments of specific base pairs length, designed as a size reference for linear PCR product. CPG methylation is heritable, tissue specific and correlate with gene expression. CPG methylation on 3' extends on restriction enzyme cleavage. Restriction enzyme leakage is blocked, when the recognition sequence is methylated by the cognate methyl's cleavage rate, which is slowed significantly by methylation. CPG sites or CG sites are the region of DNA Cytosine-phosphate-guanine, in the linear sequence of bases along its length. CpG is shorthand for -Cphosphate-G (guanine) "that is cytosine and guanine, separated by only one phosphate, its critical function is to fight with infection from environmental toxins. The linear display of the plasmid PBR 322:. 
Solanum lycopersicum chlorophyll a/b-binding protein Cab-3A genes, partial cds

GenBank: AH001373.2

GenBank Graphics

AH001373.2 Solanum lycopersicum chlorophyll a/b-binding protein Cab-3A genes, partial cds

\begin{abstract}
AAAACACAATTCAATTCATTTCTTTTTATTTATTAAACCATGGCTGCTTCTACAATGGCTCTTTCCTCCT CTACTTTCGCCGGAAAGACGGT GAAACTCGCACCATCTTCTTCTGAAATCACTGGAAATGGGAGAAT TAC TATGAGGAAGACTGCCGCCAAGCCCAAGCCAGCTTCCTCT GGTAGCCCAT GGNNNNNNNNNNNNNNNNNN NNNNNNNNNNNNNNNNNNNNNNNNNNNNNNNNNNNNNNNNNNNNNNNNNNNNNNNNNNNNNNNNNNNNNN NNNNNNNNNNNNAGTTTGGTTCATGCACAAAGCATTTTGGCTATTTGGGCTTGCCAAGTTGTGTTGATGG GAGCCGTTGAGGGTTACCGTAT TGCT GGT GGGCCTCTTGGTGAGGTT GTT GATCCAC TTTACCCTGGTGG TAGCTTTGACCCATTGGGCCTT GCTGAAGACCCAGAGGCT TTCGCTGAGCTCAAGGTAAAGGAGATCAAG AACGGCAGACTTGCTATGTTCTCCATGTTTGGATTCTTTGTTCAAGCTAT TGTCACCGGAAAGGGTCCAT TGGAGAACCTTGCCGACCACAT TGCCGACCCAGTTAACAACAACGCCTGGGCCT TTGCCACAAACTT TGT TCCCGGAAAGTGA
\end{abstract}

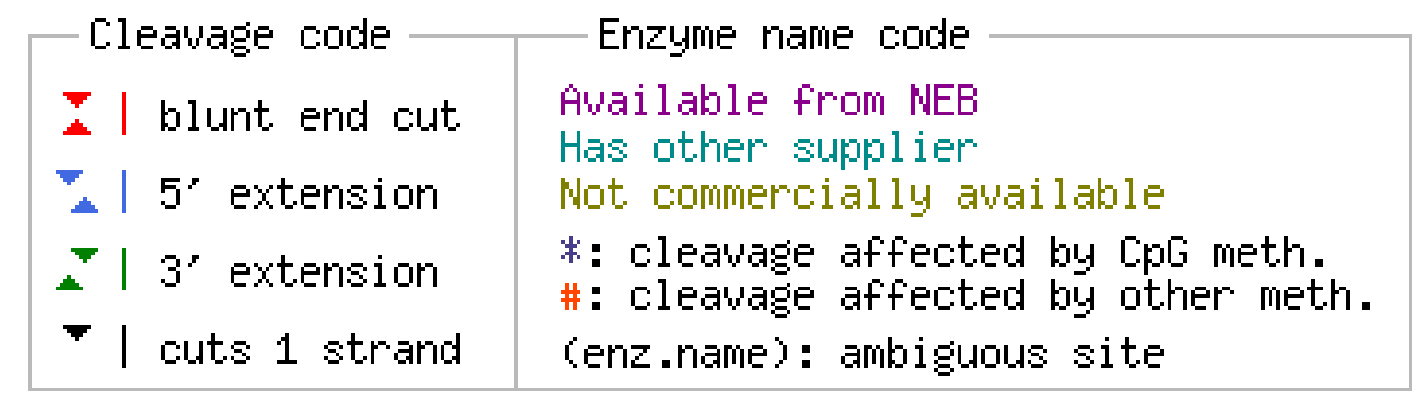

Figure 1

\title{
CONCLUSIONS
}

Restriction enzymes cleavage is blocked, when the recognition sequence is methylated by the cognate methyl's cleavage rate slowed significantly by methylation. Bases highlighted in red and blue form parts of restriction enzymes' recognition sites. CPG methylation is heritable tissue specific and correlated with gene expression. CPG methylation play role in differentiation and gene expression, if the original DNA/RNA sequence is circular, then both linear and circular displays are offered. They provide the most convenient way to manipulate individual gene and move them from one vector to another.

\section{ACKNOWLEDGEMENTS}

We extend our sincere thanks to "Dr. Savita Sanger "Vice chancellor "of Jharkhand ray university, Ranchi, India for kindly providing us the platform to carry out this research.

\section{REFRENCES}

1. Andreas D. Baxevanis, B. F. Fracis Quellette, ”A practical guide to the analysis of Gene and protein.3RD Edition October

2. 2004. Published by Wiley, John and Sons.

3. A.M. Maxam, W. Gilbert A new method for sequencing DNA Proc. Natl. Acad. Sci. U. S.A., 74 (1977), pp. 560-564 
4. Baxevanis D. Andreas, Quellete Francis B.F., A Practical guide to the Analysis of gene and Proteins.,3rd Edition October 2004, Published by Wiley, john and Sons

5. Higgins, D. G.; Sharp, P. M. (1989). "Fast and sensitive multiple sequence alignments on a microcomputer". Computer Applications in the Biosciences (CABIOS) 5(2): 151-153.doi:10.1093/bioinformatics/5.2.151. PMID 2720464.

6. Madden T. (2002).The NCBI handbook, 2nd edition, Chapter 16, The BLAST Sequence Analysis Too.

7. Mount. David 2004, Bioinformatics:-sequence \$ Genome Analysisll, published by Cold spring Harbour laboratory press

8. M.L. Metzger Emerging technologies in DNA sequencing Genome Res., 15 (2005), pp. 1767-1776

9. NCBI Resource Coordinators (2012). "Database resources of the National Center for Biotechnology Information". Nucleic Acids Research 41 (Database issue): D8-D20.

10. Open reading frame". U.S. National Library of Medicine. 2015-10-19. Retrieved 2015-10-22.

11. Pingoud, A. and Jeltsch, A. (2001) Structure and function of type II restriction end nucleases. Nucleic Acids Res., 29, 37053727.

12. Roberts, R.J., Vincze, T., Posfai, J. and Macelis, D. (2003) REBASE-restriction enzymes and methyltransferases. Nucleic Acids Res., 31, 418-420.

13. Saiki, R.K., Gelf and, D.H., Stoffel, S., Scharf, S.J., Higuchi, R., Horn, G.T., Mullis, K.B. and Erlich, H.A. (1988) Primerdirected enzymatic amplification of DNA with a thermos table DNA polymerase. Science, 239, 487-491.[11]. Lander, E.S. and Botstein, D. (1986) Strategies for studying heterogeneous genetic traits in humans by using a linkage map of restriction fragment length polymorphisms. Proc. Natl Acad. Sci. USA, 83, 7353-7357.

14. Taylor Willie, Higgins Des 2000, Bioinformatics :Sequence structure and database practical approach “,1st Edition October 2000, Published by Oxford university press

15. Whitworth, W.A. (1901) Choice and Chance with One Thousand Exercises. Fifth edition. Deighton Bell, Cambridge. [Reprinted by Hafner Publishing Co., New York, 1959.

16. Zanet, J.; Benrabah, E.; Li, T.; Pelissier-Monier, A.; Chanut-Delalande, H.; Ronsin, B.; Bellen, H. J.; Payre, F.; Plaza, S. (2015)."Pri s ORF peptides induce selective proteasome-mediated protein processing". Science. 349 (6254): 1356-1358. doi:10.1126/science.aac5677. ISSN 0036-8075. 